\title{
Kepuasan Pasien Stagnan di Instalasi Gawat Darurat (IGD) di Kupang
}

\author{
Nana Rochana $^{1^{*}}$, Noeh Nuwa Djogotuga ${ }^{2}$ \\ ${ }^{1}$ Departemen Ilmu Keperawatan, Fakultas Kedokteran, Universitas Diponegoro, Semarang, Indonesia \\ ${ }^{2}$ RSUD Prof Dr WZ Yohannes Kupang, Nusa Tenggara Timur, Indonesia \\ na2rochana@gmail.com
}

\begin{abstract}
Introduction: The quality of nursing services in the Emergency Department was greatly affected by the high number of stagnant patients resulting in their satisfaction. However, limited evidence was shown about the satisfaction level of stagnant patients in the Emergency Department in Indonesia. This study aims to know the satisfaction level of stagnant patients on the services in an Kupang Emergency Department.

Methods: The total sample in this study was 109 respondents recruited by an accidental sampling method. Data were taken using a questionnaire of Brief Emergency Department Patient Satisfaction Scale (BEPSS); and analyzed using descriptive statistics (frequency and percentage).

Results: The results of this study showed that as many as $89 \%$ of stagnant patients were satisfied with Emergency Department's services. The responsiveness dimension had the highest level of stagnant patient satisfaction (99.1\%) compared to the tangible dimension (78.9\%). The quality of service provided to stagnant patients in the emergency department should be improved especially on the tangible dimension though the majority of patients were happy with the service.

Suggestion: This study suggests to the hospital to manage a comfortable ED surrounding to the patients.
\end{abstract}

Keywords : Emergency Department, Satisfaction Level, Stagnant Patient.

\begin{abstract}
Abstrak
Pendahuluan: Peningkatan jumlah pasien stagnan di Instalasi Gawat Darurat (IGD) sangat mempengaruhi kualitas dan kuantitas pelayanan keperawatan kepada pasien dimana hal tersebut berujung kepada kepuasan pasien. Akan tetapi, bukti yang menunjukkan gambaran tingkat kepuasan pasien stagnan di IGD di Indonesia masih terbatas. Tujuan penelitian ini adalah untuk mengetahui tingkat kepuasan pasien stagnan terhadap pelayanan IGD di Kupang, Indonesia.

Metode: Total sampel dalam penelitian ini adalah 109 responden yang direkrut menggunakan metode accidental sampling. Data diambil menggunakan kuesioner Brief Emergency Department Patient Satisfaction Scale (BEPSS); dan dianalisis menggunakan satatistik deskriptif (frekuensi dan persentase).

Hasil: Hasil penelitian menunjukkan $89 \%$ pasien stagnan puas terhadap pelayanan IGD. Tingkat kepuasan pasien stagnan tertinggi pada dimensi responsiveness $(99,1 \%)$ dan yang terendah pada dimensi tangible $(78,9 \%)$. Kualitas pelayanan yang diberikan kepada pasien stagnan di IGD masih perlu ditingkatkan terutama pada dimensi tangible walaupun mayoritas pasien puas terhadap pelayanan IGD.
\end{abstract}

Saran: Penelitian ini menyarankan agar rumah sakit dapat menata lingkungan yang aman, nyaman dan tenang di IGD.

Kata Kunci: Instalasi Gawat Darurat, Pasien Stagnan, Tingkat Kepuasan. 


\section{PENDAHULUAN}

Peningkatan jumlah kunjungan pasien di IGD mengakibatkan terjadinya penumpukan pasien stagnan setelah diputuskan untuk dirawat inap (Setyoadi, Deviantony, 2017). Stagnan merupakan suatu keadaan dimana pasien tidak dapat pindah ke ruangan rawat inap lebih dari 8 jam setelah diputuskan untuk rawat inap yang disebabkan oleh beberapa faktor salah satunya karena pasien tidak mendapatkan ruang perawatan (ACEM, 2014). Institute of Medicine (IOM) dalam Lewis (Coil, Flood, Belyeu, Young, Kaji, \& Lewis, 2016) menyarankan untuk memindahkan pasien ke ruangan rawat inap dalam jangka waktu 4-6 jam setelah diputuskan rawat inap untuk mencegah terjadinya crowding yang dapat menyebabkan potensi terjadinya kesalahan medis, keterlambatan dalam pelayanan sehingga kualitas pelayanan berkurang.

Faktor penyebab terjadinya stagnan di ruang IGD antara lain keterbatasan tempat tidur dan fasilitas penunjang di ruangan rawat inap, jumlah sumber daya yang terbatas, banyaknya pasien yang datang, keputusan keluarga, administrasi (Lewis et al., 2016; Nurmansyah, Susilaningsih, \& Setiawan, 2014; Timporok \& Mulyadi, 2015). Hasil penelitian Vicellio et al. (2013) menyimpulkan bahwa pasien yang stagnan di IGD berdampak negatif terhadap tingkat kepuasan pasien. Pasien merasa tidak aman karena tingkat kebisingan sangat tinggi, ketersediaan tenaga perawat yang kurang sehingga mempengaruhi tingkat kepuasan terhadap pelayanan.

Kepuasan pasien merupakan ungkapan emosi yang dapat berupa perasaan senang atau kecewa yang muncul setelah membandingkan sesuatu yang diharapkan atau diinginkan dengan hasil atau outcome dari suatu produk pelayanan
(Kotler \& Keller, 2007). Tingkat kepuasan pasien dapat dilihat dari beberapa dimensi antara lain: dimensi tangible (bentuk fisik), dimensi reliability (kehandalan), dimensi responsiveness (ketanggapan), dimensi assurance (jaminan), dan dimensi empathy (empati) (Kotler \& Keller, 2007, p.1997).

Jumlah kunjungan pasien di Instalasi Gawat Darurat di sebuah rumah sakit di Kupang pada tahun 2015 sebanyak 22.102 pasien, 2016 sebanyak 22.572 pasien dan 2017 sebanyak 23.166 pasien. Jumlah pasien rawat inap yang tertahan di IGD perhari 10 pasien dengan lama waktu stagnan antara 2-6 jam setelah diputuskan rawat inap dan terkadang lebih dari 1-2 hari. Walaupun hasil penelitian Vicellio et al. (2013) menunjukkan bahwa peningkatan pasien stagnan di IGD berpengaruh terhadap tingkat kepuasan pasien terhadap pelayanan, namun belum ditemukan penelitian tentang tingkat kepuasan pasien stagnan di Indonesia. Berdasarkan data fenomena dan hasil studi pendahuluan tersebut, peneliti tertarik meneliti tentang "Tingkat Kepuasan Pasien Stagnan Terhadap Pelayanan di Instalasi Gawat Darurat (IGD) di Kupang”. Penelitian ini bertujuan untuk mengetahui tingkat kepuasan pasien stagnan terhadap pelayanan IGD di Kupang, Indonesia.

\section{METODE}

Penelitian ini merupakan penelitian deskriptif kuantitatif. Penelitian dilakukan di sebuah ruang IGD di Kupang sejak bulan April sampai dengan bulan Mei 2019. Jumlah sampel dalam penelitian ini sebanyak 109 yang dihitung menggunakan rumus Slovin dan direkrut menggunakan teknik accidental sampling. Adapun kriteria inklusi adalah: pasien kriteria triase hijau dan kuning, kesadaran pasien composmentis dengan GCS 14-15, dan 
masih tinggal di IGD lebih dari dua jam setelah diputuskan rawat inap, sedangkan kriteria eksklusi meliputi pasien dengan penurunan kesadaran, dan keterbatasan kemampuan membaca dan menulis.

Instrumen yang digunakan dalam penelitian ini adalah kuesioner baku yaitu Brief Emergency Department Patient Satisfaction Scale (BEPSS)(Atari \& Atari, 2015) dengan jumlah pernyataan sebanyak 20. Kuesioner ini terdiri dari 5 dimensi: dimensi tangible (fisik), dimensi reliability (kehandalan), dimensi responsiveness (ketanggapan), dimensi assurance (jaminan) dan dimensi empathy (empati). Instrumen asli BEPSS sudah mendapatkan ijin dari pencipta untuk digunakan dan dinyatakan valid dari hasil uji baca dan reliabel dengan nilai koefisien alpha Chronbach 0,88. Instrumen BEPSS diterjemahkan ke dalam bahasa Indonesia dan diterjemahkan ulang ke dalam bahasa Inggris melalui dua penerjemah bahasa yang berbeda. Hasil terjemahan dan terjemahan ulang dikonfirmasikan dengan kuesioner asli oleh seorang ahli untuk melihat adanya perbedaan arti. Kuesioner versi bahasa Indonesia kemudian dilakukan uji face validity terhadap lima responden. Data yang diperoleh dianalisis menggunakan frekuensi dan persentase.

Penelitian ini telah mendapatkan ethical clearance dari komisi etik penelitian kesehatan RSUD dr. Moewardi dengan no 480/IV/HREC/2019 dan juga telah mendapatkan ijin penelitian dari Rumah Sakit tempat penelitian ini dilaksanakan. Semua responden telah dijelaskan tentang penelitian dan memberikan informed consent sebelum berpartisipasi dalam pengisian kuesioner. Prinsip anonymity, privacy, and confidentiality juga diterapkan dalam penelitian ini.

\section{HASIL}

Tabel 1. Karakteristik responden $(\mathrm{n}=109)$

\begin{tabular}{|c|c|c|c|}
\hline No & Variabel & $\mathrm{f}$ & $\%$ \\
\hline \multirow[t]{3}{*}{1.} & Jenis kelamin & & \\
\hline & - Perempuan & 58 & 53,2 \\
\hline & - Laki-laki & 51 & 46,8 \\
\hline \multirow[t]{7}{*}{2.} & Usia & & \\
\hline & - $\quad 17-25$ tahun & 24 & 22 \\
\hline & - $\quad 26-35$ tahun & 4 & 3,7 \\
\hline & - $\quad 36-45$ tahun & 9 & 8,3 \\
\hline & - $\quad 46-55$ tahun & 25 & 22,9 \\
\hline & - $\quad 56-65$ tahun & 33 & 30,3 \\
\hline & $-\quad>65$ tahun & 14 & 6,4 \\
\hline \multirow[t]{3}{*}{3.} & Kriteria triase & & \\
\hline & - Kuning & 80 & 73,4 \\
\hline & - $\quad$ Hijau & 29 & 26,6 \\
\hline \multirow[t]{4}{*}{4.} & & Mean & SD \\
\hline & Lama stagnan (jam) & 4,79 & 3,21 \\
\hline & Min & 2 & \\
\hline & $\operatorname{Max}$ & 18 & \\
\hline
\end{tabular}

Hasil penelitian menunjukkan bahwa sebagian besar responden adalah perempuan $(53,2 \%)$, berusia 56-65 tahun $(30,3 \%)$, dan berada pada label triase kuning $(73,4 \%)$. Rata rata lama waktu stagnasi pasien IGD adalah 4,79 $\pm 3,21$ jam dengan lama minimal menunggu adalah 2 jam dan lama maksimal menunggu adalah 18 jam (tabel 1).

Tabel 2. Tingkat Kepuasan $(\mathrm{n}=109)$

\begin{tabular}{lcc}
\hline Kategori & f & $\%$ \\
\hline Puas & 97 & 89.0 \\
Kurang Puas & 12 & 11.0 \\
\hline Jumlah & 109 & 100 \\
\hline
\end{tabular}

Tabel 2 menunjukkan bahwa mayoritas responden yaitu sebanyak 97 pasien stagnan $(89 \%)$ merasa puas dengan pelayanan IGD. 
Tabel 3. Dimensi Tingkat Kepuasan $(\mathrm{n}=109)$

\begin{tabular}{lcccc}
\hline & \multicolumn{2}{c}{ Puas } & \multicolumn{2}{c}{ Kurang Puas } \\
& $\mathrm{f}$ & $\%$ & $\mathrm{f}$ & $\%$ \\
\hline Tangibles & 86 & 78,9 & 23 & 21,1 \\
Reliability & 92 & 84,4 & 17 & 15,6 \\
Responsiveness & 108 & 99,1 & 1 & 0,9 \\
Assurance & 97 & 89,0 & 11 & 11,0 \\
Empathy & 98 & 89,9 & 11 & 10,1 \\
\hline
\end{tabular}

Tabel 3 menunjukkan bahwa berdasarkan dimensi tingkat kepuasan paling tinggi adalah dimensi responsiveness $(99,1 \%)$ dan yang paling rendah pada dimensi tangible $(78,9 \%)$.

Tabel 4 menunjukkan bahwa lingkungan gawat darurat yang tenang dan sunyi pada dimensi tangible merupakan item yang paling banyak tidak disetujui $(32,2 \%)$ dan perilaku dokter yang sopan pada dimensi responsiveness merupakan item yang paling banyak disetujui $(72,5 \%)$.

\section{PEMBAHASAN}

\section{Tingkat Kepuasan}

Hasil penelitian menunjukkan bahwa mayoritas pasien stagnan merasa puas terhadap pelayanan di IGD. Hasil penelitian sebelumnya yang mendukung tentang tingkat kepuasan pasien stagnan belum peneliti temukan. Akan tetapi terdapat beberapa hasil penelitian tentang tingkat kepuasan pasien secara umum yang telah dilakukan di beberapa rumah sakit seperti Rumah Sakit Haji Jakarta (Kariasa, 2013), Rumah Sakit Advent Bandung (Tomsol, 2016), dan RSUD dr. Rasidin Padang (Gusty \& Putry, 2017), dengan rata-rata antara $76,06 \%$ sampai dengan $90 \%$ responden menyatakan puas terhadap pelayanan yang diberikan.

Tingkat kepuasan pasien stagnan terhadap pelayanan di IGD hampir sama dengan tingkat kepuasan pasien di IGD secara umum walaupun pasien stagnan menunggu dalam waktu yang cukup lama sebelum mendapatkan tempat untuk dirawat inap. Hal ini mungkin dapat disebabkan karena rata rata waktu menunggu pasien stagnan masih dalam rentang waktu normal dari length of stay di IGD (4,79 jam) walaupun terdapat pasien yang menunggu sampai 18 jam di IGD. Asusmsi ini didukung oleh penelitian Parker dan Marco (2014) yang menyatakan bahwa waktu tinggal di IGD yang lama menurunkan tingkat kepuasan pasien IGD $(\mathrm{p}=0,000)$.

Hasil penelitian ini juga diasumsikan terjadi karena peran serta pihak manajemen dalam meningkatkan kualitas pelayanan IGD. Manajemen rumah sakit tersebut terus melakukan pembenahan dalam memberikan pelayanan yang lebih baik kepada pasien dan keluarga. Akreditasi rumah sakit menuntut pihak manajemen untuk memberikan perubahan yang lebih baik.

\section{Dimensi Tangible (Bukti Fisik)}

Hasil penelitian menunjukkan bahwa dimensi tangible mempunyai tingkat kepuasan yang terendah dari keempat dimensi lainnya. Hasil ini sejalan dengan hasil penelitian Septiani (2016) yang menunjukkan bahwa tingkat kepuasan pasien di Sumedang pada dimensi tangible juga merupakan yang paling rendah (68\%). Dimensi tangible merupakan dimensi yang mempunyai pengaruh tertinggi terhadap kepuasan secara keseluruhan.

Dimensi tangible (bukti fisik) dalam kualitas layanan merupakan ungkapan nyata kepuasan yang diberikan seseorang kepada lingkungan fisik sekitar sesuai dengan penggunaan dan pemanfaatan yang dirasakan (Nursalam, 2015). 
Tabel 4. Sebaran Item Dimensi Kepuasan Pasien

\begin{tabular}{|c|c|c|c|c|c|c|}
\hline Dimensi & Item & $\begin{array}{l}\text { STS } \\
\text { f(\%) }\end{array}$ & $\begin{array}{l}\text { ATS } \\
\mathbf{f}(\%)\end{array}$ & $\begin{array}{c}\mathbf{A S} \\
\mathbf{f}(\%)\end{array}$ & $\begin{array}{c}\text { SS } \\
\mathbf{f}(\%)\end{array}$ & Total \\
\hline \multirow[t]{2}{*}{ Tangible } & $\begin{array}{l}\text { Lingkungan IGD tenang dan } \\
\text { sunyi }\end{array}$ & $9(8,3)$ & $26(23,9)$ & $54(49,5)$ & $20(18,3)$ & 109 \\
\hline & $\begin{array}{l}\text { Ruang IGD memiliki alat } \\
\text { yang lengkap dan baik }\end{array}$ & & $16(14,7)$ & $49(45,0)$ & $44(40,4)$ & 109 \\
\hline \multirow[t]{2}{*}{ Reliability } & $\begin{array}{l}\text { Waktu tunggu sebelum } \\
\text { ketemu dokter sudah sesuai }\end{array}$ & & $23(21,1)$ & $43(39,4)$ & $43(39,4)$ & 109 \\
\hline & $\begin{array}{lr}\text { Saya } & \text { akan } \\
\text { merekomendasikan rumah } & \text { rakit ini kepada kenalan saya }\end{array}$ & $2(1,8)$ & $11(10,1)$ & $63(57,8)$ & $33(30,4)$ & 109 \\
\hline \multirow[t]{2}{*}{ Responsiveness } & $\begin{array}{l}\text { Perawat memberitahu } \\
\text { tentang perawatan yang } \\
\text { harus dijalani }\end{array}$ & $1(0,9)$ & $6(5,5)$ & $58(53,2)$ & $44(40,4)$ & 109 \\
\hline & Perilaku dokter sopan & & $4(3,7)$ & $26(23,8)$ & $79(72,5)$ & 109 \\
\hline \multirow[t]{2}{*}{ Assurance } & $\begin{array}{l}\text { Perilaku staf bagian } \\
\text { pendaftaran baik }\end{array}$ & $1(0,9)$ & $14(12,8)$ & $44(40,4)$ & $50(45,9)$ & 109 \\
\hline & $\begin{array}{l}\text { Keluarga dapat } \\
\text { menghabiskan waktu yang } \\
\text { cukup di samping pasien }\end{array}$ & $3(2,8)$ & $11(10,1)$ & $40(36,7)$ & $55(50,5)$ & 109 \\
\hline \multirow[t]{2}{*}{ Empathy } & $\begin{array}{l}\text { Perawat membebaskan saya } \\
\text { dari rasa sakit dengan baik }\end{array}$ & $4(3,7)$ & $9(8,3)$ & $48(44,0)$ & $48(44,9)$ & 109 \\
\hline & $\begin{array}{l}\text { Dokter menghabiskan waktu } \\
\text { yang cukup untuk } \\
\text { memeriksa saya }\end{array}$ & $1(0,9)$ & $9(8,3)$ & $49(45,0)$ & $50(45,9)$ & 109 \\
\hline
\end{tabular}

sts = sangat tidak setuju, ats=agak tidak setuju, as=agak setuju, ss= sangat setuju.

Pada dimensi tangible, banyak responden menyatakan tidak setuju (32,2\%) dengan kondisi lingkungan IGD yang tenang dan sunyi. Peningkatan jumlah kunjungan pasien di IGD mengakibatkan terjadinya penumpukan pasien stagnan setelah diputuskan untuk rawat inap yang berdampak pada keadaan lingkungan IGD menjadi tidak tenang (Deviantony, Ahsan, \& Setyoadi, 2017). Hasil ini didukung pula oleh penelitian Singer et al. (2013) yang menyimpulkan bahwa pasien merasa tidak aman karena tingkat kebisingan sangat tinggi sehingga mempengaruhi tingkat kepuasan terhadap pelayanan.

\section{Dimensi Reliability (Kehandalan)}

Hasil penelitian menunjukkan bahwa dimensi reliability merupakan dimensi dengan tingkat kepuasan nomor dua terendah dari semua dimensi. Hasil penelitian ini berbeda penelitian Marpaung
(2016) di Medan. Penelitian tersebut menyatakan bahwa dimensi reliability merupakan dimensi yang mempunyai pengaruh paling dominan terhadap kepuasan pasien dengan koefisien regresi sebesar 0,497. Pada penelitian ini, ketidakpuasan pasien IGD pada dimensi reliability ini tidak menyebabkan rendahnya tingkat kepuasan pasien IGD secara umum. Hal ini dapat disebabkan karena tingkat kepuasan pasien pada dimensi reliability masih tergolong cukup tinggi $(84,4 \%)$.

Inti dimensi reliability adalah kehandalan yang harus dimiliki pemberi layanan, mengetahui akan prosedur kerja, cara kerja, memperbaiki berbagai keterbatasan atau masalah pada prosedur kerja dan mampu melakukan arahan yang tepat dan jelas kepada setiap bentuk pelayanan kepada masyarakat, sehingga memberikan dampak positif atas pelayanan 
tersebut (Nursalam, 2015).

Hasil penelitian menunjukkan bahwa meskipun pasien stagnan merasa puas dengan waktu tunggu bertemu dokter, akan tetapi masih terdapat beberapa pasien stagnan yang tidak akan merekomendasikan IGD tersebut kepada orang lain. Jika pelayanan yang diberikan kepada pasien sesuai dengan yang diharapkannya maka pasien akan merasa puas dan akan merekomendasikan atau menganjurkan kepada orang yang membutuhkan (Kariasa \& Setiawan, 2013). Baik atau tidaknya kualitas pelayanan akan mempengaruhi tingkat kepuasan pasien. Jika kualitas pelayanan yang dirasakan sama atau bahkan lebih dari yang diharapkan maka pelayanan dikatakan memuaskan (Marpaung, 2016).

\section{Dimensi Responsiveness (Ketanggapan)}

Hasil penelitian menunjukkan bahwa tingkat kepuasan pasien stagnan pada dimensi responsiveness adalah tingkat kepuasan yang tertinggi dibandingkan keempat dimensi lainnya. Hal ini menunjukkan bahwa ketanggapan dari pemberi pelayanan memberikan kesan positif kepada penerima pelayanan. Ketanggapan merupakan suatu respon dari berbagai keluhan mengenai bentuk pelayanan sehingga menghasilkan suatu respek positif (Nursalam, 2015). Dimensi responsiveness pada penelitian ini mempunyai tingkat kepuasan yang lebih tinggi bila dibandingkan dengan penelitian Septiani (2016) di Sumedang yang menunjukkan bahwa $57 \%$ pasien merasa puas pada pelayanan di IGD pada dimensi ini. Hal ini dapat disebabkan karena mayoritas pasien stagnan mempunyai label triase warna kuning $(73,4 \%)$. Kondisi pasien yang urgent menuntut petugas IGD baik perawat dan dokter untuk memberikan respon yang cepat dan tanggap.

Hasil penelitian juga menunjukkan bahwa pasien stagnan merasa puas atas informasi yang diberikan oleh petugas akan perawatan dirinya dan juga atas perilaku yang sopan dari petugas. Salah satu unsur dimensi ketanggapan adalah pemberian informasi penting yang detail, lugas, padat, jelas dan akuntabel tentang masalah pelayanan yang didapatkan oleh penerima layanan. Informasi yang jelas tentang segala hal terkait perawatan pasien akan membantu mengurangi tingkat kecemasan pasien dan meningkatkan kepuasan (Nursalam, 2015).

\section{Dimensi Assurance (Jaminan)}

Hasil penelitian menunjukkan bahwa tingkat kepuasan pasien stagnan pada dimensi assurance berada ditengah antara tingkat tinggi dan tingkat rendah atau dengan kata lain berada pada tingkat sedang. Meskipun berada pada tingkat sedang, tingkat kepuasan dimensi assurance pada penelitian ini lebih tinggi dari penelitian Kaban, Kandou, dan Lapian (2015) tentang kepuasan pasien di Manado. Kaban et al. (2015) melaporkan bahwa tingkat kepuasan pasien di IGD dari dimensi assurance hanya sebesar $64.2 \%$. Kinerja pemberi layanan menjadi kunci penting jaminan kepuasan penerima layanan. Jaminan ini meyakinkan konsumen bahwa petugas handal dan mampu bertindak secara mandiri dan profesional. (Nursalam, 2015).

Hasil penelitian juga menunjukkan bahwa pasien stagnan merasa puas dengan kinerja petugas administrasi akan tetapi masih meras perlu untuk meningkatkan kehadiran keluarga pasien di IGD. Dukungan keluarga kepada pasien sangat diperlukan dalam proses perawatan. Kehadiran keluarga dapat membantu proses perawatan pasien dan juga dapat mengurangi tingkat kecemasan pasien dan keluarga itu sendiri sehingga dapat mempercepat proses penyembuhan pasien (Ningsih, 2019). 
Manusia sebagai salah satu faktor penentu kualitas pelayanan yang diberikan kepada publik diharapkan memiliki sumber daya yang berkualitas sehingga dapat memberikan pelayanan yang berkualitas (Herlambang, 2016). Pemberi layanan kesehatan diharapkan mampu menjamin bahwa pelayanan mereka secara nyata dapat memberikan kepuasan kepada konsumen, disamping juga sebagai bentuk komitmen yang tinggi terhadap tugas dan fungsi mereka terhadap institusi atau organisasi tempat bekerja (Nursalam, 2015).

\section{Dimensi Empathy (Empati)}

Hasil penelitian menunjukkan bahwa tingkat kepuasan pasien stagnan pada dimensi empathy merupakan tingkat kepuasan nomor dua tertinggi dari semua dimensi. Tingkat kepuasan dimensi empathy pada penelitian ini jauh lebih tinggi dari hasil penelitian Kaban et al. (2015) yang mengungkapkan bahwa tingkat kepuasan pasien IGD di Manado pada dimensi empathy hanya sebesar $54,2 \%$. Perhatian, sikap serius, simpati, pemahaman dan keterlibatan pihak terkait perlu ditunjukkan dalam memberikan pelayanan, dimana hal tersebut adalah suatu bentuk sikap empati (Nursalam, 2015).

Hasil penelitian juga menunjukkan bahwa pasien stagnan merasa puas dengan usaha perawat dalam mengurangi nyeri pasien dan cukupnya waktu yang dihabiskan perawat dan dokter untuk menangani pasien. Hal ini menggambarkan bahwa empati sebagai bagian dari perilaku caring telah mampu ditunjukkan oleh perawat IGD. Asumsi ini didukung oleh penelitian Aupia, Lee, Liu, Wu, dan Mills (2018) yang menunjukkan bahwa empati perawat baik dari sudut pandang pasien maupun dari sudut pandang perawat itu sendiri dalam kategori baik $(M=3,23$ dan $\mathrm{M}=3,34)$.

Walaupun secara keseluruhan tingkat kepuasan pada dimensi empathy adalah baik, masih terdapat ketidakpuasan pasien terhadap sikap empati petugas IGD. Hal ini dimungkinkan disebabkan karena dampak dari pasien stagnan terhadap pasien itu sendiri adalah tidak terpenuhnya beberapa kebutuhan perawatan (Damayanti \& Sutono, 2017; Hilman, 2011; Nurmansyah et al., 2014; Tumbuan, 2015) Tidak terpenuhnya kebutuhan perawatan pasien stagnan itu salah satu penyebabnya ketidakpuasan pasien terhadap pelayanan petugas IGD.

Penelitian ini mempunyai beberapa keterbatasan yaitu hanya dilakukan pada satu IGD sehingga hasil penelitian ini belum bisa untuk digeneralisasikan ke tingkat populasi yang lebih luas. Keterbatasan yang lain adalah dengan merekrut pasien yang tinggal di IGD dalam waktu kurang dari 6 jam. Hal ini dapat mempengaruhi hasil penelitian karena batasan karakteristik pasien stagnan yang tidak jelas.

\section{KESIMPULAN DAN SARAN}

Hasil penelitian ini menyimpulkan bahwa kualitas pelayanan yang diberikan kepada pasien stagnan di IGD masih perlu ditingkatkan terutama pada dimensi tangible dan reliability walaupun mayoritas pasien puas terhadap pelayanan IGD. Penelitian ini merekomendasikan agar IGD rumah sakit mampu menata lingkungan IGD menjadi lebih nyaman bagi pasien serta meningkatkan kompetensi perawat agar pasien percaya dan puas terhadap kehandalan perawat. Penelitian ini juga merekomendasikan agar penelitian selanjutnya dapat memberi batasan yang jelas akan karakteristik pasien stagnan di IGD. 


\section{UCAPAN TERIMA KASIH}

Peneliti berterima kasih kepada seluruh responden, pihak RS tempat penelitian di Kupang, Departemen Ilmu Keperawatan Universitas Diponegoro dan semua pihak yang telah membantu proses penelitian ini dari awal sampai akhir.

\section{DAFTAR PUSTAKA}

ACEM. (2014). Emergency department design guidelines. Third Sect. Australian College for Emergency Medicine.

Aupia, A., Lee, T. T., Liu, C. Y., Wu, S. F. V., \& Mills, M. E. (2018). Caring behavior perceived by nurses, patients and nursing students in Indonesia. Journal of Professional Nursing, 34(4), 314-319.

Atari, M., \& Atari, M. (2015). Brief emergency department patient satisfaction scale (BEPSS): Development of a new Practial instrument. US National Library of Medicine National Institutes of Health. Emergency, 3(3), 103-108.

Coil, C. J., Flood, J. D., Belyeu, B. M., Young, P., Kaji, A. H., \& Lewis, R. J. (2016). The effect of emergency department boarding on order completion. Annals of Emergency Medicine, 67(6), 730-736.e2. doi: 10.1016/j.annemergmed.2015.09.018.

Damayanti, P. \& Sutono. (2017). Faktorfaktor yang beresiko terjadinya pasien stagnan di Instalasi Gawat Darurat. Jurnal Keperawatan Klinis dan Komunitas, 1(2), 81-89.
Deviantony, F., Ahsan., \& Setyoadi (2017). Analisa faktor yang berhubungan dengan waktu tunggu pasien setelah keputusan rawat inap diputuskan di zona kuning instalasi gawat darurat RSUD dr. Iskak Tulungagung. Nurse Line Journal, 2(2), 1-8.

Gusty, R. M., \& Putry, Z. (2017). Hubungan respons time perawat pada pelayanan gawat darurat dengan kepuasan pßasien di IGD RSUD dr. Rasidin Padang. Padang: Universitas Andalas.Tesis.

Herlambang, S. (2016). Manajemen pelayanan kesehatan rumah sakit. Jogjakarta: Gosyen Publishing.

Hilman, K., Forero, R., \& McCharty, S. (2011). Accses Block and Emergency Department Overcrowding. Critical Care, 15, 216.

Kaban, W., Kandou G. D., \& Lapian, L. H. (2015). Kepuasan pasien di instalasi gawat darurat RSUP Prof. DR. Kanduo Manado. E-jurnal Keperawatan, 3(2), 37-47.

Kariasa, M., \& Setiawan, I. (2013). Tingkat kepuasan pasien terhadap pelayanan perawat di unit gawat darurat Rumah Sakit Haji Jakarta. Jakarta: FIK UI. Tesis.

Kotler, P., \& Keller, K. (2007). Manajemen pemasaran. Jakarta: PT Index.

Coil, C. J., Flood, J. D., Belyeu, B.M., Young, P., Kaji, A.H., \& Lewis, R.J. (2016). The Effect of emergency department boarding on order completion. Annals of Emergency 
Medicine, 67(6), 730-736.e2. doi: 10.1016/j.annemergmed.2015.09.018.

Marpaung, M. D. P. (2016). Analisis pengaruh kualitas pelayanan terhadap kepuasan pasien rawat inap di RSUP H. Adam Malik Medan. Universitas Sumatera Utara. Diperoleh dari http://repository.usu.ac.id/handle/1234 $56789 / 64980$

Ningsih, S.A. (2019). Hubungan dukungan keluarga dengan respon cemas pada anak usia sekolah (6-12 tahun) saat dilakukan pemasangan infus. Jurnal Keperawatn Muhammadiyah Bengkulu, 7(2), 589-596.

Nurmansyah, E., Susilaningsih, F. S., Setiawan, S. (2014). Tingkat ketergantungan dan lama perawatan pasien rawat observasi di IGD. Jurnal Keperawatan Padjajaran, 2(3), 191201. Doi: 10.24198/jkp.v2i3.89.g84

Nursalam. (2105). Manajemen keperawatan: Aplikasi dalam praktik keperawatan. Jakarta: Salemba Medika.

Parker, B. T., \& Marco, C. (2014). Emergency department length of stay: accuracy of patient estimates. The western journal of emergency medicine, 15(2), 170-175. Doi: 10.5811/westjem.2013.9.15816
Septiani A. (2016). Pengaruh faktor-faktor kualitas pelayanan terhadap kepuasan pasien di instalasi gawat darurat RSUD Kabupaten Sumedang. Coopetition, VII(1), 1-21.

Timporok, O. P., \& Mulyadi, M. R. (2015). Faktor-faktor yang mempengaruhi waktu tunggu pasien di instalasi gawat darurat medik RSUP Prof. DR. RD. Kandou Manado. e Jurnal Keperawatan (eKP), 3(2), 1-8.

Tomsol, S. (2016). Hubungan Pelayanan Perawatan dengan Kepuasan Pasien di Unit Gawat Darurat Rumah Sakit Advent Bandung. Tesis.

Tumbuan, A. N, Kumaat, L., \& Malara, R. (2015). Hubungan respons time perawat dengan tingkat kecemasan pasien kategori triase kuning di IGD RSU GMIM Kalooran Amurang. Ejournal Keperawatan, 3(2), 1-8.

Viccellio, P., Zito, J. A., Sayage, V., Chohan, J., Garra, G., Santora, C., \& Singer, A. J. (2013). Patients overwhelmingly prefer inpatient boarding to emergency department boarding. The Journal of Emergency Medicine, 45(6): 942-6. doi: 10.1016/j.jemermed.2013.07.018. 